\title{
Article
}

\section{Exploring the emotional dimension of visitors' satisfaction at cultural events}

Christou, Prokopis, Sharpley, Richard Anthony john and Farmaki, Anna

Available at https://clok.uclan.ac.uk/22290/

Christou, Prokopis, Sharpley, Richard Anthony john orcid iconORCID: 00000002-2135-3206 and Farmaki, Anna (2018) Exploring the emotional dimension of visitors' satisfaction at cultural events. Event Management, 22 (2). pp. 255-269. ISSN 1525-9951

It is advisable to refer to the publisher's version if you intend to cite from the work. http://dx.doi.org/10.3727/152599518X15173355843389

For more information about UCLan's research in this area go to http://www.uclan.ac.uk/researchgroups/ and search for <name of research Group>.

For information about Research generally at UCLan please go to http://www.uclan.ac.uk/research/

All outputs in CLoK are protected by Intellectual Property Rights law, including Copyright law. Copyright, IPR and Moral Rights for the works on this site are retained by the individual authors and/or other copyright owners. Terms and conditions for use of this material are defined in the policies page.

\section{CLoK}

Central Lancashire online Knowledge www.clok.uclan.ac.uk

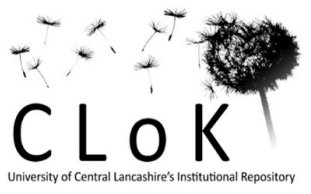




\title{
EXPLORING THE EMOTIONAL DIMENSION OF VISITORS' SATISFACTION AT CULTURAL EVENTS
}

\author{
PROKOPIS CHRISTOU,* RICHARD SHARPLEY,† AND ANNA FARMAKI* \\ *Cyprus University of Technology, Limassol, Cyprus \\ †University of Central Lancashire, Preston, UK
}

\begin{abstract}
Cultural events have emerged as a destination instrument for sharing local folk culture with visitors, aspiring to provide them with satisfying experiences at the same time as conveying socioeconomic benefits to the local community. However, studies of the visitor satisfaction process as a measure of the success of staging a cultural event remain noticeably lacking. Adopting an ethnographic approach, this article investigates visitor satisfaction by considering the emotional dynamics involved - a psychological dimension that remains largely overlooked within the tourism context. Fieldwork findings reveal the important role of senses in this process and pinpoint precise emotions that impact on (dis)satisfaction and intentions. Based on the research outcomes, the article then proposes a model conceptualizing this process that is of relevance beyond the specific context of events. The study envisages a tighter link between the fields of tourism and psychology, given the potentially rewarding outcomes this might yield.
\end{abstract}

Key words: Visitor satisfaction; Emotions; Senses; Cultural events; Tourism; Psychology; Cyprus

Introduction

Traditions and rituals that can be traced back over the centuries continue to be manifested in a variety of contemporary events, such as fairs, festivals, parades, and other forms of cultural celebration (Bowdin, Allen, O’Toole, Harris, \& McDonnell, 2012). Fundamental to such cultural events are the experiences and meanings attached to them, particularly for participants (Ziakas \& Boukas, 2014). That is, their roots typically lie in the community's celebration of culturally meaningful occasions and, thus, community participation may maintain cultural traditions, strengthen a local sense of place, and enhance community social capital (Arcodia \& Whiford, 2006; Derrett, 2003).

Address correspondence to Dr. Prokopis Christou, Lecturer in Tourism Management, Department of Hotel and Tourism Management, Cyprus University of Technology 115 Spyrou Araouzou Street, Limassol, 3036, Cyprus. Tel: ++357 25002117; Fax: ++357 25002633; E-mail: prokopis.christou@cut.ac.cy 
However, at the same time cultural events are increasingly being recognized and promoted as tourism attractions (Stokes, 2008). Generally, "events are an important motivator of tourism, and figure prominently in the development and marketing plans of most destinations" (Getz, 2008, p. 403). Indeed, destinations have long developed and hosted an enormous diversity of events for a variety of purposes, from broadly increasing visitor numbers and receipts to more specific goals, such as enhancing the destination brand (Jago, Chalip, Brown, Mules, \& Ali, 2003). However, cultural events have emerged as an instrument for tourism development. Though not a new phenomenon, destinations are increasingly exploiting and promoting local culture though events and festivals, primarily to increase the contribution of tourism to the local economy. For example, Litvin, Pan, and Smith (2013) found that higher accommodation prices during festivals in Charleston provided a significant boost to the local economy while cultural events are an effective means of lengthening the tourist season, such as Easter festivities in Sardinia (Giudici, Melis, Dessì, \& Ramos, 2013). Other benefits may also accrue from cultural events; For example, Houghton (2001) found that wine festivals in Victoria resulted in additional revenue and winery recognition, enhanced region awareness and community harmony, new customers for the community, and positive future visitation intentions.

However, staging successful events remains a challenge, particularly as an element of a tourism strategy (Stokes, 2008). That is, augmenting a tourism destination's "offer" through the development and promotion of events may not necessarily achieve the desired objectives, such as increased visitor numbers and spending or an extension of the tourist season. For example, Cyprus has been attempting to enrich its tourism product through the promotion of cultural events but, despite a significant increase in the number of such events, the success of this strategy remains questionable (Coastal Tourism Organization [CTO], 2015). Not only is it widely acknowledged that "the success of the destination depends upon tourists receiving satisfying experiences" (Sharpley, 2014, p. 47) or that understanding tourists' experiences is fundamental to destination success (del Bosque \& Martin, 2008) but also, as others note (Ellert, Schafmeister, Wawrzinek, \& Gassner, 2015), the staging of an event is further complicated by the need to provide an overall satisfactory experience.

Thus, it is surprising that in comparison to research into tourist satisfaction more generally, relatively few attempts have been made to explore the satisfaction of (cultural) event visitors. As Kim, Boo, and Kim (2013) observe, despite an increase in research in terms of volume and scope over the last three decades, attention has remained focused on a relatively limited number of topics, primarily related to functional or operational issues, while more limited research has undertaken into event visitor motives and experiences. Similarly, Mair and Whitford (2013) found that some event issues (e.g., logistics) have been comprehensively researched while attendee motivations and behavior remain an important area for future research. Grappi and Montanari (2011) furthermore note that future research would benefit from the analysis of different (e.g., gastronomic) cultural festivals; indeed, Pan and Huan (2013) specifically called for "more qualitative studies . . . to address the experience of festival attendees and participants" (p. 117). Most significantly, perhaps, although the role of emotions in customer satisfaction has long been considered in the marketing literature (Martin, O'Neill, Hubbard, \& Palmer, 2008) and, to a lesser extent, in tourism (Chatzigeorgiou, Christou, Kassianidis, \& Sigala, 2009; del Bosque \& Martin, 2008), it has by and large been overlooked in the context of events (Y. Lee, Lee, Lee, \& Babin, 2008; Wood \& Moss, 2015). Similarly, Prayag, Hosany, and Odeh (2013) called for a more holistic understanding of the role of emotions in tourist experiences while, more specifically, Hosany and Prayag (2013) called for further research into negative emotions and their relevance to tourist behavior. Furthermore, previous research into emotions within the tourism context has been primarily undertaken retrospectively rather than in actual time (after rather than during the event); hence, providing potentially inaccurate accounts of actual experiences given the dynamic and time-dependent nature of emotions (Prayag, Hosany, Muskat, \& Chiappa, 2017).

The purpose of this article is to begin to address this gap in the literature. Specifically, drawing on real-time research among visitors to a number of cultural events in Cyprus (i.e., while attending the event) through an ethnographic approach, 
it explores visitor satisfaction from an emotional perspective. In so doing, it not only contributes to understanding of event visitors' satisfaction processes in general and the psychological (i.e., emotional) dynamics involved, but it also provides the basis for the development of a conceptual model of the visitor satisfaction process that embraces an affective, emotional component. Furthermore, it contributes to debates surrounding which precise emotions are most significant in a tourism context (Nawijn, Mitas, Lin, \& Kerstetter, 2013) and which specific factors - as distinct from those at mainstream events - are necessary for the successful staging cultural events that may impact positively on the emotional state and satisfaction of attendees and their emotional ties to both the event and the destination as a whole. However, the first task is to review briefly the relationship between emotions and satisfaction as a framework for the subsequent research.

\section{Emotions and Satisfaction}

The last decade has witnessed an increase in academic interest in the concept of emotions from a variety of disciplinary perspectives, with many commentators acknowledging the significance of emotions in everyday interpersonal interactions and social activities (see Barbalet, 2004). As Kalat (2011) stated, "all of our emotions, within limits, provide richness to our experiences" (p. 437).

However, debate surrounds how emotions may be characterized (Ben-Ze'ev, 2000). Broadly, they may be described as organizers of meaning, providing direction to human senses and encouraging certain sets of actions (e.g., the desire to run away from something fearful). In other words, emotions orient people to what they see, hear, smell, and taste, and, to a great extent, direct behavior (Zautra, 2003). Nevertheless, no consensus exists among psychologists as to how many types of emotions people experience. Some propose only a short list, including happiness, sadness, anger, fear, and disgust; in contrast, others include nostalgia (Yeh, Chen, \& Liu, 2012), contempt, interest, frustration, love, embarrassment, boredom, and even surprise (Kalat, 2011), although the latter is generally regarded as a cognitive reaction as opposed to an emotion (Spinoza, 1989). However, despite the lack of an agreed taxonomy of emotions, scientists concur on the broad classification of emotions into positive and negative. For instance, Plutchik (1980) divided eight primary emotions into positive (joy, acceptance, anticipation, and surprise) and negative (anger, fear, disgust, and sadness). However, certain emotions may not be considered categorically negative; for example, fear and anger are sometimes positively correlated with survival. Hence, the positive or negative nature of a particular emotion depends on intraindividual, person-environment processes and ecological considerations.

The role of emotions has also been explored within the context of tourism and events, mainly owing to their direct relationship with satisfaction (Hosany \& Gilbert, 2010). Indeed, the relationship between emotions and satisfaction more generally has been long recognized, the work of marketing researchers (e.g., Bagozzi, Gopinath, \& Nyer, 1999; Nyer, 1997) being highly influential in establishing this relationship. With the field of tourism, specific positive/negative basic emotions (joy and fear) have, for example, been found to influence (mountaineering) tourist satisfaction (Faullant, Matzler, \& Mooradian, 2011). Prayag et al. (2013) examined the relevance of three positive emotions (joy, love, positive surprise) and one negative emotion (unpleasantness) to the satisfaction and behavioral intentions of (heritage) tourists, while the findings of Prayag et al. (2017) revealed that tourists' emotional experiences act as antecedents of perceived overall image and satisfaction evaluations. In another study, Hosany and Prayag (2013) identified emotional response patterns among tourists (the delighted, unemotionals, negatives, mixed, and passionate), which were found to differ according to satisfaction level. Del Chiappa, Andreu, and Gallarza (2014) similarly found that those visitors (in a museum setting) with more positive emotions reported being more satisfied with their experience than those with less positive emotions, concluding that emotions are more significant than cognitive aspects in shaping visitors' satisfaction. Research within the events context has also revealed that emotions directly affect attendees' (of a festival) hedonism and satisfaction (Grappi \& Montanari, 2011). The importance of emotions to experience and behavior beyond the actual event has also been highlighted; for instance, J. Lee, Kyle, and Scott 
(2012) found that satisfied visitors at a festival also develop an emotional attachment to the festival host destination and, ultimately, become loyal to that destination.

In their model, del Bosque and Martin (2008) attempted to clarify the interrelationships between emotions and satisfaction, as well as between expectations and intentions, concluding that preconceived destination image influences expectations, and that expectations and emotions impact on satisfaction, which then has a significant influence on intentions. Others have noted the various elements that influence the emotional state of event attendees, hence shaping their satisfaction and, subsequently, future intentions. For example, Grappi and Montanari (2011) identified particular elements of a cultural event that may impact on emotions and consequently on satisfaction and intentions to revisit, including staff, facilities, and atmosphere. They suggest, among other things, that attractive festival surroundings that may heighten sensations and positive feelings. Indeed, the role of senses within this dynamic relationship is not to be ignored. That is, (in)tangible elements (e.g., people, settings and food) may address the human senses as a whole (holistically) which, according to Macpherson (2011), constituted the different ways people have of perceiving the world, such as seeing, hearing, touching, smelling, and tasting. From a psychological perspective, there is much evidence to suggest the effect of a stimulus on the emotional state of people, such as the sight of a terrifying bear which may result in fear (see Kalat, 2011). More specifically, Sharpley and Jepson (2011) revealed a positive emotional effect as a result of the interaction of visitors with a particular rural setting, which apparently embraced a holistic and agreeable (that is, pleasant) sensual experience resulting of various senses' stimuli; such as in this case, from different (in)tangible elements found in the countryside environment. These elements-such as for instance the pleasant natural surroundings-act as (e.g., eye and smell) stimuli while addressing agreeably all the senses of the user/consumer, causing a rather holistic pleasant sensual experience, or what could be referred to as a "HASE," an acronym to describe a "holistic agreeable senses experience."

The increasing attention paid to emotions by tourism academics may furthermore be explained by not only the connection between emotions and satisfaction, but also their dynamic influence they hold in shaping future intentions and memory (après-travel) arousal. For example, research has demonstrated that people tend to remember events that were surprising (Kalat, 2011; Parzuchowski \& Szymkow-Sudziarska, 2008). Emotions have also been identified as a key determinant in transforming satisfaction into repeat (tourism) business (Chatzigeorgiou et al., 2009) while emotion-based satisfaction was found to be a better predictor of future behavioral intention than cognitive measures of satisfaction (Martin et al., 2008; Wood \& Moss, 2015). In contrast, negative emotions experienced by festival attendees led to a sense of dissatisfaction and a direct weakening of intentions to revisit, pointing to a clear link between emotions, satisfaction and future intentions (Grappi \& Montanari, 2011). In a similar vein, Tronvoll (2011) confirmed that the negative emotion of "frustration" was the best predictor of complaints towards service providers.

Therefore, it is unsurprising that researchers suggest that the tourism/events industry should seek to provide positive emotional visitor experiences. Arguably, this task may not be as challenging as it might appear, given that more positive emotions are evidently experienced by tourists while on vacation. For example, Nawijn et al. (2013) confirmed previous evidence that tourists tend to experience a higher intensity of positive rather than negative emotions while on holiday. Similarly, Hede and Hall (2012), who explored the emotions of Australian tourists at Gallipoli commemorations, concluded that although not all tourism experiences elicit hedonically related emotions, the outcome of the experience can nevertheless be positive. More generally, del Bosque and Martin (2008) suggested that destinations should offer a mixture of emotions to enrich individuals' experience in order to achieve true satisfaction and, eventually, loyalty to the destination, although Nawijn et al. (2013) suggested that tourism providers should attempt to create higher positive emotion among tourists towards the end of their holiday. In other words, the absence of a peak in holiday happiness may focus tourists' memory on the end of the holiday, when they experience the least positive emotions; vacation memories, they argue, are an important predictor of future purchase behavior, thus linking emotions with memory arousal. 
Nevertheless, as del Bosque and Martin (2008) noted, greater understanding of the tourist satisfaction process is still required for the more effective management of the event visitor experience. This is not to say that tourist satisfaction has not benefitted from significant academic attention-quite the contrary-yet recent studies argue that affective or emotional components in the satisfaction process have been largely overlooked (Martin et al., 2008). Nonetheless, the influence of emotions on satisfaction and future intentions in service contexts has become increasingly acknowledged (White \& Yu, 2005 ) and, thus, customer satisfaction is now more commonly explored within a cognitive-affective framework. Yet, Maguire and Geiger (2015) highlighted that a comprehensive understanding of service consumption emotions still remains elusive; indeed, although the centrality of emotions to all significant human activity is now acknowledged, understanding of their role in such core activities remains undeveloped (Barbalet, 2004). Nevertheless, White and Yu (2005) observed that tourism practitioners have much to gain by taking emotions into consideration, thereby potentially enriching the tourist experience and enhancing satisfaction and loyalty. Perhaps this is one of the main reasons that commentators stress the need for further research into the influence of emotions in tourism-related activities, including event attendance (Wood \& Moss, 2015; Yan, Zhang, \& Li, 2012). More specifically, Nawijn et al. (2013) called for further research to identify those emotions that are most important in a tourism context. Despite some noteworthy studies related to the topic, such as those referred to above, research into the emotional dimensions of tourists' experiences remains largely underexplored (Hosany \& Gilbert, 2010). This is particularly so within the context of cultural events, hence the research that this article now turns to.

\section{Study Methods}

As previously stated, the purpose of this research was to investigate event visitor satisfaction through the lens of emotions. It focused on visitors at cultural events in Cyprus, seeking to identify whether overall positive or negative emotions were experienced and to what extent these impacted on levels of satisfaction. Therefore, an ethnographic approach was employed, a method considered to be particularly appropriate to the context of events for gaining a deeper understanding of audiences (Mackellar, 2013). Ethnographers attempt to understand social meanings in terms of what is meaningful to people and their behavior through observation, listening, and talking with them (Ciaran, 2007). In tourism studies, McCabe (2007) emphasized the benefits of ethnomethodologies to the in-depth exploration of people and their experiences. The observation component of ethnography contributes to comprehending emotions, because expressions (mostly occurring in a social context; see Sacco \& Hugenberg, 2009) betray emotional states (Kalat, 2011). For the purpose of this study, the observed behavior of visitors and their personal experiences at cultural events was noted. The study targeted both international/ domestic visitors, as suggested by others (Prayag et al., 2017). Informal interviews ( $n=$ around five per event), which were open in structure and direction to allow access to respondents' experiences and underlying feelings (Bryman, 2004), were conducted with randomly selected visitors at cultural events (see Tables 1 and 2), the purpose being to elicit their felt emotions and initial expectations, whether they regarded their experience as satisfactory, and their future intentions following the event.

The informal interviews took place towards the end or immediately following the event, hence responding to calls for real-time research into tourists' emotions (Nawijn et al., 2013; Prayag et al., 2017), while allowing a holistic perspective of the event and emotions experienced to be provided by respondents. Examples of questions that were employed included, for example: "how did you feel when this [for example, particular incident] happened?" or "do you recall previous events where you experienced similar emotions?"

Table 1

Respondents' profile

\begin{tabular}{lc}
\hline Visitors & Actual No. of Visitors (\%) \\
\hline Males & $66(53 \%)$ \\
Females & $59(47 \%)$ \\
Total & $125(100 \%)$ \\
Domestic & $86(69 \%)$ \\
International & $39(31 \%)$ \\
Total & $125(100 \%)$ \\
\hline
\end{tabular}


Table 2

\begin{tabular}{lllc} 
Cultural Events Information & & & \\
\hline Cultural Event Groups (Clusters)/Specific Event & Area & \multicolumn{1}{c}{ Actual Location } & Event Date (D/M/Y) \\
\hline Religious events & & & \\
Christmas market/show & Urban & Larnaka city center & $12 / 20 / 2014$ \\
Christmas show & Rural & Lemesos rural area & $12 / 23 / 2014$ \\
Easter festivity/event & Rural & Pitsilia region & $4 / 18 / 2014$ \\
Epiphany Day event & Urban & Larnaka city center & $1 / 6 / 2014$ \\
Byzantine Christmas Choir & Urban & Faneromeni-Nicosia & $12 / 18 / 2015$ \\
Ethnic/Cultural celebration & & & \\
25th of March National Day & Urban & Larnaka promenade & $3 / 25 / 14$ \\
Green Monday event & Rural & Ayios Tychonas village & $3 / 3 / 2014$ \\
Carnival event & Urban & Old Lemesos & $3 / 2 / 2014$ \\
1st of October- National Day & Urban & Nicosia/Old Nicosia & $4 / 1 / 2015$ \\
1st of April- National Day & Rural & Pitsilia Area & $4 / 1 / 2014$ \\
Cultural fairs/events & & & \\
Paniyiri/Folkloric Dances & Urban & Araddippou & $10 / 18 / 2014$ \\
Traditional Paniyiri & Urban & Larnaca (west suburb) & $9 / 20 / 2014$ \\
Traditional Paniyiri & Rural & Arakapas village & $8 / 30 / 2015$ \\
Paniyiri/Folkloric Dances & Rural & Athienou village & $9 / 21 / 2014$ \\
Traditional Paniyiri & Rural & Lemesos west region & $12 / 1 / 2015$ \\
Traditional festivals & & & \\
Wine festival & Urban & Lemesos & $8 / 30 / 2014$ \\
Flood (Kataklysmos) festival & Urban & Larnaka promenade & $6 / 8 / 2014$ \\
Koumandaria festival & Rural & Pitsilia Area & $10 / 10 / 2014$ \\
Choroesperida event & Rural & Lemesos district & $8 / 16 / 2015$ \\
Folkloric festival & Rural & Troodos area & $10 / 11 / 2014$ \\
Art related event & & & $8 / 20 / 2014$ \\
Poetry night event & Urban & Nicosia city center & $4 / 5 / 2014$ \\
Theatrical presentation & Urban & Larnaka & $4 / 18 / 2014$ \\
Art exhibition/Event & Rural & Lemesos rural area & $6 / 22 / 2015$ \\
Cultural song event & Urban & Larnaka & $8 / 17 / 2015$ \\
Cultural night & Rural & Lemesos rural area & \\
\hline & & & \\
\hline & & & \\
& & &
\end{tabular}

There are no strict rules for determining the number of sites included in ethnography because the validity of this approach does not depend on minimum sample sizes (Mariampolski, 2006). For this study, Cyprus was divided into urban/rural settings while a total number of 25 (small/large, profit/nonprofit oriented, of public/private interest) events were randomly selected from five broad event clusters that shared analogous content; certain events (those recognized by UNESCO) were purposely selected. A combination of ethnographer roles was employed to permit active involvement, observation, and informal interviews, while avoiding potential risks; the validity of ethnography may be threatened by reactivity, subjectivity, and a "going native" situation (Bryman, 2004). Therefore, emphasis was placed on achieving rigor in data collection and credibility and relevance of outcomes (Kitto, Chesters, \& Grbich, 2008) while protocol rules (i.e., privacy) were followed.
Although there are no guidelines on numbers of participants in ethnographic studies, reliability issues were addressed by involving more than a few participants (Daengbuppha, Hemmington, \& Wilkes, 2006). Indeed, 125 informal interviews were conducted and a random selection rule was enforced. Field notes were kept (Bryman, 2004) while during the analysis process, the ethnographer followed suggestions to pattern and model the findings in relevant general themes (Beymor-Davis, 1997; Ciaran, 2007); more specifically: findings were related to expectations, emotions experienced, and future intentions. This was followed by a process of comparing information and finding general linkages, similarities, and differences between respondents' responses. The study commenced in January 2014 and once some degree of saturation was achieved (Mariampolski, 2006) and sufficient data to reach conclusions was gathered, ended in December 2015. 
With regards to the study limitations, although an ethnographic approach may include as little as one person's (autoethnography) findings, it may be debatable whether the total number of respondents included in this particular study was sufficient, particularly when compared to other tourism satisfaction studies, such as that by del Bosque and Martin (2008), in which more than 800 valid responses were collected. Also, this study does not confirm the intention/actual behavior association of visitors. Furthermore, there were some cases in which respondents experienced difficulties in expressing certain emotions. Additionally, the study did not identify any significant differences based on gender or other cultural/demographic criteria; further research in this regard is recommended. Although cultural events were grouped in five distinct categories, the division may be blurred owing certain events falling into two or more clusters. And finally, choosing events that may be an accurate representation of the whole population was not possible given that each event, despite any similarities with others, is unique in terms of orientation, organization, and origins.

\section{Research Outcomes}

Generally, the majority of the respondents (around $70 \%$ ) expressed overall positive emotions (joy, interest, enthusiasm, pride, and nostalgia) related to their cultural event experience. Only $10 \%$ expressed negative emotions (disappointment, anger, and frustration) while around $15 \%$ revealed a positive and negative emotional amalgamation, such as interest and fear, or pride and sadness. A small percentage (about $5 \%$ ) could not pinpoint which exact emotion they felt while attending a particular event.

\section{Findings Related to Expectations, Perceived Image, and Emotions}

Almost all participants stated that they had certain expectations and somehow a "clear image" of what the event entailed, supporting this through their exposure to promotional leaflets, media, social marketing, and previous personal experience. Additionally, overall positive emotions (i.e., contempt, joy, and happiness) were reported by those who felt that the event promoted a joyful spirit-a "pleasant aura" as one respondent expressed it - or the outcome of the event met, or even exceeded, their initial expectations. However, strong positive emotions (e.g., enthusiasm) were expressed less by those who felt that an event was not well organized or was perceived to be of "lesser value" compared to other similar events that they might have attended in the past. Similarly, strong positive emotions were less frequently expressed by a minority of respondents (less than 10\%) who had higher, unmet expectations resulting from, for example, previous personal experience or inaccurate promotion. In these cases, respondents reported negative emotions and overall dissatisfaction. Specifically, negative emotions such as disappointment, anger, and frustration were reported by attendees whose expectations were not met. This was extended to a "shocking," unpleasant (and unforeseen) experience, when dramatic circumstances (e.g., an accident) occurred at a particular event; the ethnographer's observations also support this. One respondent clarified the impact of unmet expectations as follows: "a (promotional) leaflet with fake pictures and information that would make you imagine a spectacular event. ... Not at all!"

Notable is the fact that overall satisfaction was still communicated by such visitors, provided that they experienced positive emotions (e.g., joy) during the event. Even so, "enthusiasm" was reported mostly by those who were pleasantly surprised by something of which they had few or no expectations, or those who were highly anticipating a specific event (e.g., carnival). Such respondents also recalled and articulated similarly enthusiastic emotions that they had experienced at past memorable events, such as New Year's festivities in London. Hosany and Prayag (2013) referred to such tourists who display elevated levels of joy and surprise as the delighted ones.

\section{Emotions and Senses}

Strong positive emotions, evidenced in enthusiastic verbal and nonverbal clues, were observed and communicated by those who referred to what appears to have been a satisfying holistic (involved all senses) and pleasant (agreeable) sensual experience. For example, wine festival visitors communicated positive emotions while referring to 
the "consumption" of aesthetically pleasant surroundings, folkloric music, active engagement with fermentation equipment, wine tasting, and the "delicious charcoaled village sausages!" Any distraction to this sensual experience has the potential to influence emotional states and the overall experience, even transforming it into a dissatisfying one. For example, one respondent expressed "anger" while referring to the person sitting next to him:

He smelled really bad. . . . It (unpleasant odor) was distracting me. ... I couldn't enjoy the show. . . . He got me really angry! I wanted to leave the show, it was that bad.

Likewise, others who, though not expressing negative emotions, nevertheless made reference to certain aspects that apparently "disturbed" their senses, such as in the case of cultural events that were staged at convenient, though unattractive sites (parking areas) rather than in places with appealing, traditional surroundings. Of course, findings reveal that cultural events are also subject to exogenous influences, some of which are beyond the control of organizers (for example, weather conditions), which may lead to an incomplete sensual pleasant experience. One respondent pointed out their desire for an outdoor Christmas fair to be:

accompanied with grey skies and cold weather, and why not, even some snow ... that would have been nice!

\section{Emotions and Satisfaction}

The cluster of respondents who expressed overall positive emotions (approximately 70\%) also communicated an overall satisfying (event) experience. For instance, "love" is a positive emotion that was mentioned (sporadically) by respondents who "consumed" psychological rather than tangible offerings from local people, such as genuine hospitality:

I love the way Maro (Head waitress) treats us. . . . She even invited us to her house for soup. ... I don't think that was part of her job description (laughing).... Her family was lovely. ... We keep in touch, and I'm trying to convince her to come to Scotland.
The majority of those who experienced both negative and positive emotions (approximately $15 \%$ ), as well as all those visitors who could not pinpoint/express the emotions they felt, were also unable to determine whether they were (dis)satisfied with their experience. Interestingly, although some respondents referred to positive emotions (and satisfaction), they still spoke about negative aspects of an event, such as aesthetic deficiency. For example, one respondent stated:

It felt nice watching and listening to the children (Choir) singing. . . . I guess what I truly felt was joy! . . . (later) . . . They could've done a better job with the decorations and the little (staged) houses.

All of those who expressed overall negative emotions (approximately 10\%) also voiced their dissatisfaction. However, of note is the fact that although certain respondents referred to negative emotions, they still regarded their experience as a satisfactory one; "fear," for instance was found to augment the overall experience, such as visitors reporting "fear" along with other contradictory emotions, such as excitement, when being close to fireworks. Nonetheless, the same emotion was found to be the response to an unpleasant factor that was perceived by visitors to threaten their well-being, hence affecting adversely their overall experience, such as being in overcrowded venues or in the possibility of being harmed:

It's constantly in your mind ... what if a lunatic takes out a gun and starts shooting everyone.... I never used to think like this but ... . it's very hard to block your thoughts. Especially if you have children with you.

Also, while observing the gestures, postures, and facial expressions of people in specific cases, the emotional state of respondents was further revealed (Kalat, 2011; Zhou \& Chen, 2009). The ethnographer's comments reveal the emotion of "fear" among visitors:

I notice distressed faces and fingers pointing at the sky as the storm approaches.... Organizers seem worried. . . . The thunder sound terrifies the children... . "Don't worry!" the Mayor cries ... Come inside and the show will continue as normal. 
Furthermore, despite the fact that "sadness" was reported by visitors at particular events, such as war commemoration events, they still considered their experience to be satisfactory, emphasizing in particular positive emotions such as "pride" and "admiration" (e.g., towards ethnic heroes). Specific negative emotions such as frustration and anger were also found in some cases to be exhibited towards others:

Someone needs to teach them how to organize a nice fair. The irony is that they (implying organizers) think that they know, but they know nothing.

Those who communicated such negative emotions not only communicated their dissatisfactionhence confirming the effect of negative emotions on satisfaction (Burns \& Neisner, 2006) — but also expressed their intention to share their discontent mainly with others rather than the organizers. Nevertheless, it should be noted that even the successful organization of an event may not necessary impact favorably on the emotional state of attendees; that is, apart from uncontrollable exogenous factors or external influences, such as a storm on the day of an al-fresco event, there may be other reasons why a specific event may not be valued by certain people. For example, unruly behavior at carnival festivities may create positive emotions - such as "joy"- among some visitors and negative- such as "disgust" - among others. Furthermore, respondents who communicated positive emotions made no reference to the price factor (although it should be noted that the entrance fee to those events that charged one was limited to just a few euros). Even so, when certain negative emotions, such as disappointment, were reported, the "price" element was often raised by attendees. Personal investments, not restricted to monetary factors (i.e., time and effort), were also brought up once the overall experience was perceived by visitors as dissatisfactory. The ethnographer's notes below, followed by a respondent's comments confirm this:

It took me roughly 2 hours to get here only to see people packing their stuff. The event should've lasted for at least 4 more hours.

I felt that I wasted my time, just by being here. . . . I've been in much better shows and I paid far less money for it. I'd have preferred to give my money for something else ... to go for a nice dinner with my kids.

Furthermore, although it is arguable whether boredom can be defined as a negative emotion, it is interesting that almost all those who felt "bored" at certain events not only regarded their overall experience as an unpleasant/unsatisfactory one, but also communicated a nonrevisit intention, which leads us to the last section of the study findings section, the intentions following the event experience:

Our friends told us that it (fair) is really nice, but I find it very boring. . . . Not much for the kids to do. ... There's just this rock band with some songs that I never heard before. . . I'm very disappointed.

This outcome certainly contributes to the discussion of the impacts of negative emotions on tourist behavior, a topic demanding further research, as Hosany and Prayag (2013) suggested.

\section{Future Intentions and the Metatravel Aspect}

All respondents indicated the intention to share their event experience with others, such as family members and friends, verbally, and/or through other means, such as by posting on social media. The majority of those who expressed strong positive emotions, such as joy, happiness, and surprise, not only communicated their willingness to transfer information to others, but also the intention to revisit (the event and/or the destination) at some point in the future, depending however on exogenous, or personal factors, such as:

Of course this depends on whether financial circumstances allow us to come back again. . . For the time being we are fine (economically referring) but who knows? I may be left jobless, and in that case holidays will need to be postponed.

Notable is the fact that affective strong emotions, such as love, were reported specifically by visitors who attended events in the rural, as opposed to urban, settings. Moreover, those who expressed this particular emotion were more likely to find themselves bonded with or attached to certain communities and places, and also communicated revisit 
intentions. This outcome provides an answer to Lashley's (2008) argument in regards to the importance of emotions, which are stimulated by the hospitableness involved in the host-guest transaction. Likewise, revisit intentions were additionally reported by domestic visitors who expressed certain emotions ("pride" and "nostalgia"):

I remember when my parents used to bring us here (wine festival) when we were little . . my father gave me some Koumandaria (dessert wine) and my mum was shouting at him (laughing). Till now, whenever I drink Koumandaria, I remember that night

Nonetheless, specific seasonal cultural events provided that they created strong positive emotions such as happiness and surprise, were found to be connected by respondents with a particular destination during a specific season, and hence abetted a revisit intention:

If I don't come to . . (mountainous village) I don't feel that it's Easter. . . . It's the traditions, customs, the festivities, the games they have here. . . . It's truly wonderful! Once my wife was sick and we had to stay in Nicosia (town) and it didn't feel like it was Easter.

Based on respondents' comments, this affiliation is further strengthened in the memories of such respondents, through stimuli (e.g., images), which they "consumed" at the destination and which they (un)intentionally came across even years after the event took place; for example, while browsing through photo albums. Further research outcomes indicate that visitors' emotional state though attending an event may impact on the perceived "image" that someone may have, even for the destination as a whole, and its intention to share experiences with others. For example, if negative emotions such as frustration are experienced, these may influence negatively the perception that the visitor will have of the event organizers and, perhaps, local people or even the destination as a whole. One such (local) respondent said:

This place (referring to the destination, as a whole) is full of amateurs! There's no food, no cold drinks left and the field (event place) is full of dirt and soil. I can't even hear the music!
Based on the respondents' comments, this points to the almost definite intention of providing negative word of mouth, hence stressing the importance of the nature of the interaction between tourists and service providers in the process of providing satisfying experiences (Sharpley, 2014).

\section{Discussion and Conclusions}

It is evident that the majority of the respondents in this research expressed overall positive emotions and satisfaction with only 1 out of 10 expressing negative emotions and dissatisfaction. However, this is not surprising; as previously noted, tourists experience a higher intensity of positive rather than negative emotions while on holiday (Nawijn et al., 2013). Hosany and Prayag (2013) similarly found only a small proportion of respondents constituting what they referred to as the negatives cluster, an outcome they explained by the fact that tourists tend to anticipate pleasurable experiences and avoid negative emotions. All the same, the ethnographic approach employed in this study yielded several themes. First, the study supports the outcomes of previous research with regards to the effect of emotions on visitor satisfaction (Burns \& Neisner, 2006; Del Chiappa et al., 2014; Hosany \& Prayag, 2013); specifically, a link can be identified between emotions and (dis)satisfaction among attendees, as long as the individual is able to clearly identify whether overall positive/negative emotions are experienced. However, this study reveals that despite the overall positive emotions and satisfaction expressed by most visitors, certain negative aspects were identified, such as a lack of organization by those staging the event. Thus, this study challenges the widespread view that visitor satisfaction is an indication of a successful event and in so doing contributes to debates surrounding what is a "successful" event.

Second, the findings acknowledge the pivotal role of the preconsumption stage, particularly past experiences, in shaping the visitor's overall experience. If the event elicits positive emotions, these may impact positively on the visitor's overall experience even if the event does not meet visitor expectations. Nevertheless, the role of expectations should not be undermined as positive emotions were reported by respondents who felt that an event met/exceeded their expectations. As a result, unforeseen and 
unexpected (pleasant) elements of events may lead to "enthusiasm," the activation of which is assumed to evoke memories in which similar emotions were experienced. This stresses the importance of both cognitive/affective roles in satisfaction (del Bosque \& Martin, 2008) and confirms a direct link between emotions and satisfaction (Hosany \& Gilbert, 2010). Furthermore, it highlights the significant (satisfaction-related) role of the emotion of (pleasant) surprise, as identified by Prayag et al. (2017). The fact that respondents were able to recall past experiences in which they experienced "enthusiasm" reinforces the argument that people tend to remember events that were surprising (Parzuchowski \& Szymkow-Sudziarska, 2008). Such (past) memories were evoked through similar emotions felt in recent events, indicating a close cognitive/affective association between past and current experiences. This represents the third finding of the study, which highlights the role of emotions in the satisfaction process in terms of providing an overall satisfying - and unforgettableexperience.

Additionally, positive emotions and satisfaction were communicated by those respondents who received certain pleasant psychological (e.g., love related) offerings, such as affection, offered by hosts. The role of love in terms of affection, tenderness, and caring has also been identified by Hosany and Prayag (2013) as contributing positively to the emotional state of tourists, hence forming what they referred to as the passionate cluster. However, of note is the fact that positive emotions and satisfaction were furthermore communicated by those who consumed what appears to be a holistic and pleasant (agreeable) senses' experience. That is, their experience involved an overall undistracted, satisfying sensual feeling embracing sight, hearing, taste, touch, and smell (HASE). The importance of fulfilling the senses is stressed in this study, on the basis that sensual experiences sway peoples' emotions. Parenthetically, no conclusions can be drawn on the ability of people with impaired sense abilities to express strong positive emotions. This may nonetheless be used as an important tool and "compass" by providing direction to those specific elements that need to be addressed while targeting the senses, which consecutively may impact positively on emotions and heighten overall experiences.
However, the extent to which this can be employed remains to be explored by event organizers who need to identify what specific physical and psychological elements to offer in order to enthuse the human senses. This is best illustrated in the proposed model (Fig. 1), which clearly exemplifies the overall (event attendees') satisfaction process by drawing on key themes that are identified through this study. More specifically, the model illustrates clearly a dynamic process involving the pre, during and metaexperience event stages, such as the perceived image and initial expectations visitors may hold prior to an event, the psychological and physiological "offerings" the destination and event organizers may provide to address the senses, and the impact these may have on emotional states, overall (dis)satisfaction and future intentions of attendees. The model clearly states examples of such "offerings" that may target all visitor senses and have an affective emotional outcome, such as distinct pleasant odors, local delicacies, and aesthetic surroundings. For example, psychological elements, politeness, and affective attitudes are also shown because these are part of the intangible offerings a destination, hosts, and event organizers may offer for visitor consumption. A number of precise emotions are presented, as are the direct impact these may specifically have on the satisfaction of attendees and their intentions following their experience. Factors within the macro and microenvironment and others beyond the control of event organizers that may interfere in this process, such as a terrorist threat and unruly behavior by others that may disturb the overall visitor experience, are also illustrated.

The study furthermore confirms previous findings (Burns \& Neisner, 2006; Grappi \& Montanari, 2011) of a clear relationship between negative emotions and dissatisfaction. The fact that those who communicated negative emotions, such as "frustration" and "anger," express their discontent to others reinforces the argument that the negative emotion of "frustration" is the best predictor of complaints (Tronvoll, 2011). Even so, what is noteworthy is the fact that despite the presence of negative emotions, such as "sadness," other emotions such as "pride" and "admiration" seem to counteract negative expressions and result even in an overall satisfying experience. This finding gives validity to Hede 


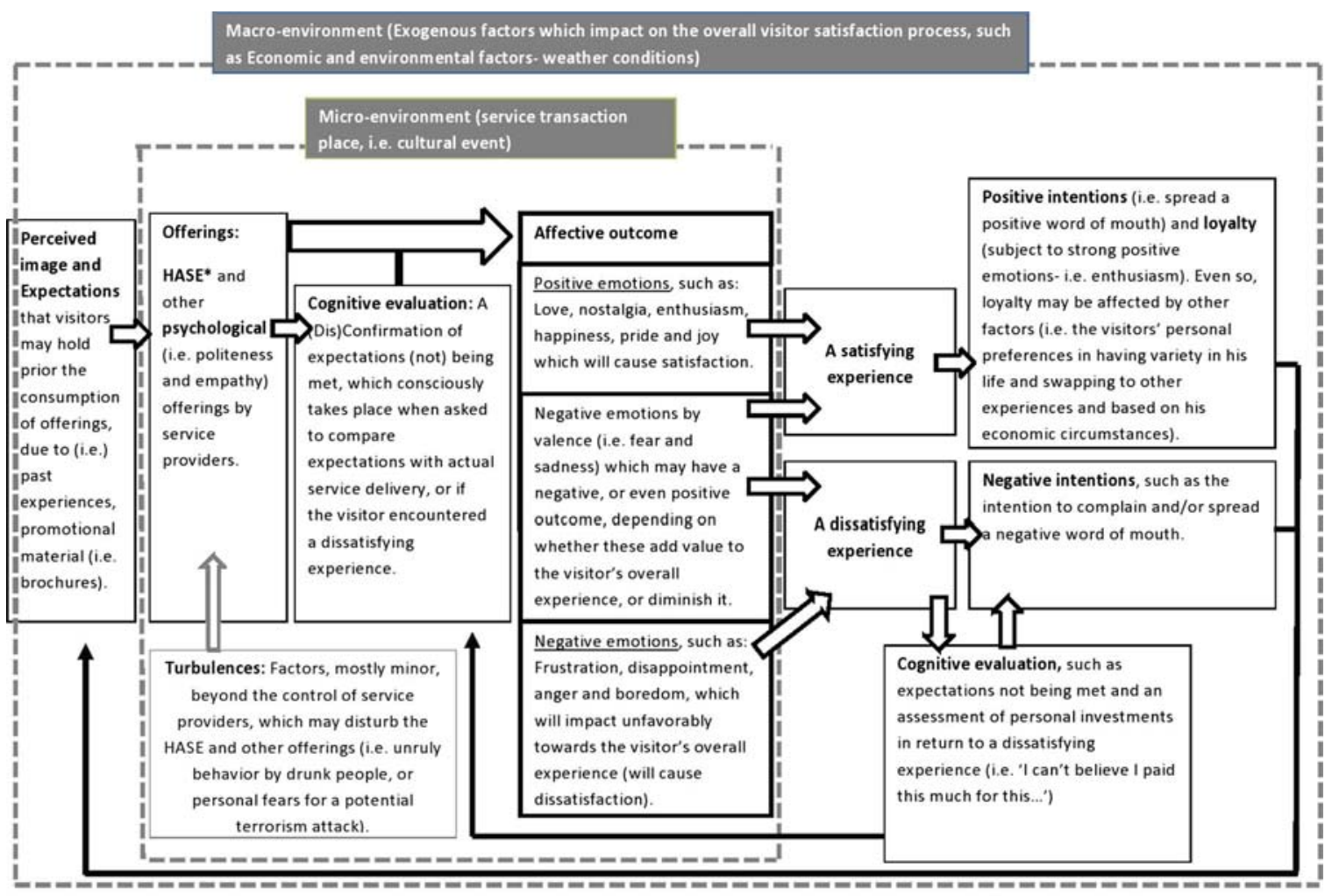

*HASE (Holistic Agreeable Senses Experience): Such offerings which aim to satisfy all (holistically) human senses in an agreeable manner (with the absence of any endogenous and exogenous incidences/factors which may disturb this process). For instance, a cultural event HASE may include aesthetical traditional well-preserved surroundings, amusing cultural music, distinct pleasant odors, the availability of local tasty/fresh food and the possibility to touch/actively engage- if desired by the visitor- in the event process (i.e. to dance).

Figure 1. The satisfaction process of event attendees.

and Hall's (2012) argument that although not all tourism experiences elicit hedonically related emotions, the outcome of the experience can be positive. Surprisingly, there were cases reported in the study in which certain negative emotions, such as sadness and fear, were perceived as more valuable to the overall experience. Even so, uncontrolled conditions and other exogenous circumstances, such as severe weather conditions, which may pose a threat to the well-being of visitors, might evoke strong negative emotions (i.e., fear/trepidation) and adversely impact on their experience.

The principal outcome of this study, despite the acknowledgement of the senses' contribution to the emotional state of people, is the fact that it pinpoints those precise emotions (namely: "love," "happiness," "pride," and "nostalgia"), which secure a satisfactory experience and positive future intentions to revisit the event and destination. This certainly contributes towards the discussion of others (e.g., Lee et al., 2012) surrounding which precise factors may enhance visitors' emotional ties with the festival and the spatial context in which the festival is experienced. For instance, seasonal cultural events associated with strong positive emotions (e.g., nostalgia) were found to be linked explicitly by visitors with a specific destination, consequently enhancing place attachment. Interestingly, specific strong positive emotions, such as "love," were evoked through relations in the countryside, further solidifying the importance of the nature of host/ guest interactions (Sharpley, 2014) and the qualities of hospitableness ("psychological offerings") in this relationship (Lashley, 2008). Nonetheless, event organizers/destinations may also practically assist in this visitor-destination "linkage" and 
place attachment, as well as memory stimuli. For instance, the "tangibilization" of the (event) experience with the offering of certain items, such as memorabilia, may lead to strong associations with a specific destination. The enhancement of such memorabilia with certain distinct (local) smells is recommended as it may lead to cognitive/affective stimulations, evoking memories/emotions felt while at the particular event/destination, once the visitor returns home.

Certain managerial implications can be drawn from this study. For instance, given that people tend to remember events that were surprising, it is suggested that event organizers strive to enthuse visitors through unexpected offerings, which will impact positively on their emotional state, thereby securing a satisfying and memorable visitor experience that they shall "recall" once they experience similar intense future emotions. What is more, event organizers should try to tangibilize the (event) experience, through certain local memorabilia, which may lead to memory arousal at a later stage. Destinations, event organizers, and hosts should furthermore seek to provide psychological pleasant offerings, such as genuine love-giving approach and qualities of hospitality, because these may nurture strong positive emotions. A holistic, pleasant (agreeable) senses' experience (HASE) should furthermore be promoted by targeting all attendees' senses, while trying to avoid unsolicited turbulences, such as unruly behavior caused by drunk people. These may be perceived by visitors as a negative aspect of an event, potentially affecting their emotional state and, consequently, their satisfaction and future intentions. More specifically, event organizers should target all senses, such as staging an event within pleasant physical surroundings (e.g., in a village square, not a parking place), aesthetic attributes (e.g., well-preserved/ decorated traditional buildings), relevant (i.e., folkloric) dances/music, availability of (local/flavorsome) food, and active-visitor engagement (e.g., self-art craft). Finally, it is suggested that event organizers complete thorough risk assessments prior the event and be prepared to address hazards through alternative actions.

To conclude, while employing anthropologiccentered ethnography with its usefulness in deep human explorations (Mackellar, 2013), this study provides important cultural event insights from a socio/psychological viewpoint, thereby providing further exploration of this topic as suggested by others (Pan \& Huan, 2014). By investigating satisfaction through emotional tools, the study responds to researchers' calls (Wood \& Moss, 2015) for further consideration of human emotions in tourismrelated activities, which remain largely underexplored (Hosany \& Gilbert, 2010). The study findings identify and promote the important, yet somehow neglected, role of senses in this process while pinpointing those precise emotions that may impact on satisfaction and metaexperience intentions. The study initiates as well as foresees a thriving potential for further research in visitor psychological states, and most importantly on further investigations of emotions and senses. The fieldwork findings are conceptualized in a model of the visitor satisfaction process, which takes into consideration cognitive/affective visitor components, as well as endo/ exogenous environmental dynamics that influence the route towards a satisfying visitor experience and its metacauses. The authors envisage that the applicability and usefulness of this model will be extended beyond the events arena, into the tourism field in general.

\section{References}

Arcodia, C., \& Whitford, M. (2006). Festival attendance and the development of social capital. Journal of Convention \& Event Tourism, 8(2), 1-18.

Bagozzi, R., Gopinath, M., \& Nyer, P. (1999). The role of emotions in marketing. Academy of Marketing Science, 27(2), 184-206.

Barbalet, J. (2004). Consciousness, emotions and science. In J. Turner (Ed.), Theory and research on human emotions (pp. 245-272). Bradford, UK: Emerald Group Publishing Limited.

Ben-Ze'ev, A. (2000). The subtlety of emotions. Cambridge, MA: MIT Press.

Beymor-Davis, P. (1997). Ethnography and information systems development: Ethnography of, for and within IS development. Information and Software Technology, 39, 531-540.

Bowdin, G., Allen, J., O’Toole W., Harris, R., \& McDonnell, I. (2012). Events management (3rd ed.). New York, NY: Routledge.

Bryman, A. (2004). Social research methods (2nd ed.). New York, NY: Oxford University Press.

Burns, D., \& Neisner, L. (2006). Customer satisfaction in a retail setting: The contribution of emotion. International Journal of Retail \& Distribution Management, 34(1), 49-66. 
Chatzigeorgiou, C., Christou, E., Kassianidis, P., \& Sigala, M. (2009). Examining the relationship between emotions, customer satisfaction and future behavioural intentions in agritourism. Tourismos: An International Multidisciplinary Journal of Tourism, 4(4), 145-161.

Ciaran, B. (2007). Information creation and the notion of membership. Journal of Documentation, 63(1), 142-164.

Coastal Tourism Organization. (2015). Strategic plan 2010-2015. Tourism: What changes with the strategy of 2010-2015. Retrieved from http://www.sigmalive.com/ archive/inbusiness/news/services/297025

Daengbuppha, J., Hemmington, N., \& Wilkes, K. (2006). Using grounded theory to model visitor experiences at heritage sites: Methodological and practical issues. Qualitative Market Research, 9(4), 367-388.

del Bosque, I. R., \& San Martín, H. (2008). Tourist satisfaction a cognitive-affective model. Annals of Tourism Research, 35(2), 551-573.

Del Chiappa, G., Andreu, L., \& Gallarza, M. (2014). Emotions and visitors' satisfaction at a museum. International Journal of Culture, Tourism and Hospitality Research, 8(4), 420-431.

Derrett, R. (2003). Festivals and regional destinations: How festivals demonstrate a sense of community and place. Rural Society, 13(1), 35-53.

Ellert, G., Schafmeister, G., Wawrzinek, D., \& Gassner, H. (2015). Expect the unexpected: New perspectives on uncertainty management and value logics in event management. International Journal of Event and Festival Management, 6(1), 54-72.

Faullant, R., Matzler, K., \& Mooradian, T. (2011). Personality, basic emotions, and satisfaction: Primary emotions in the mountaineering experience. Tourism Management, $32(6), 1423-1430$

Getz, D. (2008). Event tourism: Definition, evolution, and research. Tourism Management, 29(3), 403-428.

Giudici, E., Melis, C., Dessì, S., \& Ramos, B. (2013). Is intangible cultural heritage able to promote sustainability in tourism? International Journal of Quality and Service Sciences, 5(1), 101-114.

Grappi, S., \& Montanari, F. (2011). The role of social identification and hedonism in affecting tourist re-patronizing behaviours: The case of an Italian Festival. Tourism Management, 32(5), 1128-1140.

Hede, A., \& Hall, J. (2012). Evoked emotions: Textual analysis within the context of pilgrimage tourism to Gallipoli. In F. H. Kenneth, C. Ryan, \& A. Woodside (Eds.), Field guide to case study research in tourism, hospitality and leisure (Advances in Culture, Tourism and Hospitality Research, Vol. 6, pp. 45-60). Bingley, UK: Emerald Group Publishing.

Hosany, S., \& Gilbert, D. (2010). Measuring tourists' emotional experience toward hedonic holiday destinations. Journal of Travel Research, 49(4), 513-526.

Hosany, S., \& Prayag, G. (2013). Patterns of tourists' emotional responses, satisfaction, and intention to recommend. Journal of Business Research, 66, 730-737.
Houghton, M. (2001). The propensity of wine festivals to encourage subsequent winery visitation. International Journal of Wine Marketing, 13(33), 32-41.

Jago, L., Chalip, L., Brown, G., Mules, T., \& Ali, S. (2003). Building events into destination branding: Insights from experts. Event Management, 8(1), 3-14.

Kalat, J. (2011). Introduction to psychology (9th ed.). Belmont, CA: Wadsworth.

Kim, J., Boo, S., \& Kim, Y. (2013). Patterns and trends in event tourism study topics over 30 years. International Journal of Event and Festival Management, 4(1), 66-83.

Kitto, S., Chesters, J., \& Grbich, C. (2008). Quality in qualitative research. Medical Journal of Australia, 188(4), 243-246.

Lashley, C. (2008). Marketing hospitality and tourism experiences. In H. Oh (Ed.), Handbook of hospitality marketing management (pp. 3-31). Oxford, UK: Butterworth- Heinemann.

Lee, J., Kyle, G., \& Scott, D. (2012). The mediating effect of place attachment on the relationship between festival satisfaction and loyalty to the festival hosting destination. Journal of Travel Research, 51(6), 754-767.

Lee, Y., Lee, K., Lee, S., \& Babin, B. (2008). Festivalscapes and patrons' emotions, satisfaction and loyalty. Journal of Business Research, 61(1), 56-64.

Litvin, S., Pan, B., \& Smith, W. (2013), Festivals, special events, and the "rising tide." International Journal of Culture, Tourism and Hospitality Research, 7(2), 163-168.

Mackellar, J. (2013). Participant observation at events: Theory, practice and potential. International Journal of Event and Festival Management, 4(1), 56-65.

Macpherson, F. (2011). Philosophy of mind series: Senses: Classic and contemporary philosophical perspective. Oxford, UK: Oxford University Press.

Maguire, L., \& Geiger, S. (2015). Emotional timescapes: The temporal perspective and consumption emotions in services. Journal of Services Marketing, 29(3), 211-223.

Mair, J., \& Whitford, M. (2013). An exploration of events research: Event topics, themes and emerging trends. International Journal of Event and Festival Management, 4(1), 6-30.

Mariampolski, H. (2006). Ethnography for marketers: A guide to consumer immersion. Thousand Oaks, CA: Sage Publications.

Martin, D., O’Neill, M., Hubbard, S., \& Palmer, A. (2008). The role of emotion in explaining consumer satisfaction and future behavioural intention. Journal of Services Marketing, 22(3), $224-236$.

McCabe, S. (2007). The beauty in the form: Ethnomethodology and tourism studies. In I. Ateljevic, A. Pritchard, \& N. Morgan (Eds.), The critical turn in tourism studies: Innovative research methodologies (pp. 227-244). Oxford, UK: Elsevier.

Nawijn, J., Mitas, O., Lin, Y., \& Kerstetter, D. (2013). How do we feel on vacation? A closer look at how emotions change over the course of a trip. Journal of Travel Research, 52(2), 265-274. 
Nyer, P. U. (1997). A study of the relationships between cognitive appraisals and consumption emotions. Journal of the Academy of Marketing Science, 25(4), 296-304.

Pan, B., \& Huan, T. (2013). New perspectives on festival and events research. International Journal of Culture, Tourism and Hospitality Research, 7(2), 115-117.

Parzuchowski, M., \& Szymkow-Sudziarska, A. (2008). Well, slap my thigh: Expression of surprise facilitates memory of surprising material. Emotion, 8(3), 430-434.

Plutchik, R. (1980). The emotions. Lanham, MD: University Press of America.

Prayag, G., Hosany, S., \& Odeh, K. (2013). The role of tourists' emotional experiences and satisfaction in understanding behavioural intentions. Journal of Destination Marketing \& Management, 2(2), 118-127.

Prayag, G., Hosany, S., Muskat, B. \& Chiappa, G. (2017). Understanding the relationships between tourists' emotional experiences, perceived overall image, satisfaction and intention to recommend. Journal of Travel Research, $56(1), 41-54$.

Sacco, D., \& Hugenberg, K. (2009). The look of fear and anger: Facial maturity modulation recognition of fearful and angry expressions. Emotion, 9(1), 39-49.

Sharpley, R. (2014). Host perceptions of tourism: A review of the research. Tourism Management, 42(1), 37-49.

Sharpley, R., \& Jepson, D. (2011). Rural tourism: A spiritual experience? Annals of Tourism Research, 38(1), 52-71.

Spinoza, B. (1989). Ethics. London, UK: Everyman Classics.
Stokes, R. (2008). Tourism strategy making: Insights to the events tourism domain. Tourism Management, 9(2), 252-262.

Tronvoll, B. (2011). Negative emotions and their effect on customer complaint behavior. Journal of Service Management, 22(1), 111-134.

White, C., \& Yu, Y. (2005). Satisfaction emotions and consumer behavioral intentions. Journal of Services Marketing, 19(6), 411-420.

Wood, E., \& Moss, J. (2015). Capturing emotions: Experience sampling at live music events. Arts and the Market, $5(1), 45-72$.

Yan, Q., Zhang, H., \& Li, M. (2012). Programming quality of festivals: Conceptualization, measurement, and relation to consequences. International Journal of Contemporary Hospitality Management, 24(4), 653-667.

Yeh, S., Chen, C., \& Liu, Y. (2012). Nostalgic emotion, experiential value, destination image and place attachment of cultural tourists. In J. Chen (Ed.), Advances in hospitality and leisure (Vol. 8, pp. 167-187). Bradford, UK: Emerald Group Publishing Limited.

Zhou, W., \& Chen, D. (2009). Fear-related chemosignals modulate recognition of fear in ambiguous facial expressions. Psychological Science, 20(2), 177-183.

Zautra, A. (2003). Emotions, stress and health. New York, NY: Oxford University Press.

Ziakas, V., \& Boukas, N. (2014). Contextualizing phenomenology in event management research: Deciphering the meaning of event experiences. International Journal of Event and Festival Management, 5(1), 56-73. 